\title{
Comportamento de porta-enxertos cítricos submetidos em composições de diferentes substratos
}

\section{Carlos Alberto Fonseca do Nascimento', Jorge Hugo Iriarte Martel ${ }^{2}$ e Cristóvão Gomes Plácido Júnior ${ }^{3}$}

\footnotetext{
${ }^{1}$ Mestre em Agricultura no Trópico Úmido pelo Instituto Nacional de Pesquisa na Amazônia. Professor de Infraestrutura Rural no Instituto Federal do Amazonas - Campus Manaus Zona Leste, Brasil.

E-mail: carlosalbertofca@gmail.com 9 http://lattes.cnpq.br/5659813443891631 id https://orcid.org/0000-0002-1775-711X

${ }^{2}$ Doutor em Agronomia pela Universidade Estadual Paulista. Pesquisador Instituto Nacional de Pesquisa da Amazônia, Brasil.

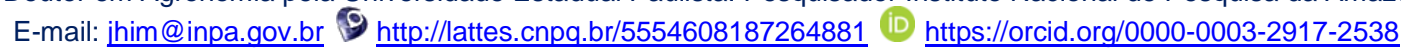

${ }^{3}$ Doutor em Agronomia Tropical pela Universidade Federal do Amazonas. Professor de Agricultura no Instituto Federal do Amazonas Campus Manaus Zona Leste, Brasil.

E-mail: cristovao.junior@ifam.edu.br htp htp://lattes.cnpq.br/1099010967540977 (iD https://orcid.org/0000-0003-0902-4511
}

RESUMO: O trabalho em questão foi desenvolvido em viveiro de mudas na área experimental da Coordenação de Pesquisas em Ciências Agronômicas (CPCA), do Instituto Nacional de Pesquisas da Amazônia (INPA), Manaus, Amazonas, nele foi avaliado o crescimento inicial de seis porta-enxertos cítricos, submetidos a cinco combinações volumétricas de substratos; utilizando o delineamento experimental inteiramente casualizado em esquema fatorial 6 X 5 . Ao longo de 240 dias foram avaliados: a) o crescimento vegetativo dos porta-enxertos em altura e diâmetro; b) acúmulo de massa seca na parte aérea e parte radicular; e c) a porcentagem de plantas aptas à enxertia. A análise revelou que o porta-enxertos "Santa Cruz", "English 264", "English 256" e "Swingle 314" são promissores à citricultura Amazonense, enquanto que as composições de substratos TPI+EBC, TPI+EBC+CP e TPI+EBC+FC foram os que proporcionaram maior crescimento vegetativo aos porta-enxertos para as condições avaliadas.

Palavras chave: Porta-enxertos. Substratos. Crescimento.

Behavior of citrus rootstocks submitted in different substrates compositions

ABSTRACT: The work in question was developed in seedling nursery in the experimental area of Research Coordination of Agricultural Sciences (CPCA), the National Institute for Amazonian Research (INPA), Manaus, Amazonas, it was evaluated the initial growth of six rootstocks citrus volumetric subjected to five combinations of substrates; using completely randomized design in a factorial $6 \times 5$. During 240 days were evaluated: a) vegetative growth of rootstocks in height and diameter; b) dry matter accumulation in the shoots and roots; and c) the percentage of plants suitable for grafting. The analysis showed that the rootstocks "Santa Cruz," "Inglês 264", "Inglês 256" and "314 Swingle" are promising for Amazonian citrus, while the compositions TPI + EBC substrates, $\mathrm{TPI}+\mathrm{CP}+\mathrm{EBC}$ and $\mathrm{TPI}+\mathrm{EBC}+\mathrm{FC}$ were the ones that provided greater vegetative growth to rootstocks for the evaluated conditions.

Keywords: Rootstocks. Substrates. Growth.

\section{INTRODUÇÃO}

O Brasil é o maior produtor mundial de frutas cítricas, com uma produção de apro- ximadamente 20 milhões de toneladas. Deste montante, a produção principal é de laranjas com uma produção acima de 17 milhões de toneladas. Atualmente o Brasil 
tem uma participação de 34\% e 56\% na produção mundial da fruta e do suco concentrado de laranja, respectivamente (IBGE, 2016; NEVES; TROMBIN, 2017).

As exportações Brasileiras de suco concentrado de laranja gera um Produto Interno Bruto (PIB) de US\$ 6,5 bilhões em todos os elos da sua cadeia produtiva e cerca de 200 mil empregos diretos e indiretos (NEVES; TROMBIN, 2017).

O Amazonas, apesar de apresentar condições climáticas favoráveis ao bom desenvolvimento da cultura com uma temperatura média de 26,7 으 e uma precipitação anual em torno de $2.300 \mathrm{~mm}$, não configura no cenário nacional como uns dos maiores produtores, com uma área colhida de apenas 2.411 hectares (ha) e uma produção de 40.329 toneladas, sendo que $100 \%$ das frutas são comercializadas de forma in natura no município (capital) de Manaus (IBGE, 2016).

A produção de laranja no Amazonas despertou o interesse dos produtores em virtude do bom preço que a fruta tem alcançado no mercado em torno de $\mathrm{R} \$ 1.500,00$ por tonelada (ALMUDI; PINHEIRO, 2013). Entretanto o rendimento da cultura ainda é considerado muito baixo, aproximadamente dezesseis toneladas por hectare, quando comparada ao Estado de São Paulo que apresenta uma produtividade acima de trinta toneladas por hectare (IBGE, 2016). Segundo Ledo et al. (1999), a diversificação dos porta-enxertos poderá contribuir na longevidade e no aumento da produtividade de plantios de citros na Amazônia Ocidental; complementado por Oliveira (2003), que diz que os porta-enxertos também afetam a precocidade da produção, o vigor da copa, a resistência à seca e às doenças, recomendando assim, diversificar os porta- enxertos em até $30 \%$ da área.

O Estado do Amazonas, assim como o restante do país, possui mais de $80 \%$ de seu pomar constituído da combinação portaenxerto limão cravo (Citrus limonia Osbeck) e a copa laranja pêra [Citrus sinensis (L.) Osbeck], porém o uso de um único portaenxerto, pode impedir que a planta manifeste todo seu potencial produtivo em outros tipos de solos e clima, além do risco de adquirir novas moléstias (SILVA; GARCIA, 1999). A falta de diversificação poderá acarretar em vulnerabilidade com dizimação de pomares, como ocorrido no caso da Tristeza dos citros (TVC), na década de 40, Gomose de Phytophthora, cancro cítrico, Clorose Variegada dos citros (CVC) e mais recentemente, com a Morte Súbita dos citros (MSC) (GRAF, 2001; SCHÄFER et al., 2006).

A muda de citros, assim como de uma série de outras fruteiras, é composta pela combinação de uma variedade portaenxerto com uma variedade copa, sendo exigidos critérios específicos em relação à formação dos porta-enxertos e da muda propriamente dita (OLIVEIRA et al., 2005). Segundo Andrade e Martins (2003), o sucesso na implantação de um pomar de citros está no plantio de mudas de qualidade, sendo, para isso, imprescindíveis à boa formação, o vigor e a sanidade da muda.

Segundo Pompeu Jr. (1991), o portaenxerto é aspecto imprescindível na produção de mudas, pois induz alterações à variedade copa no seu crescimento, longevidade, tamanho, precocidade de produção, produtividade, época de maturação, peso dos frutos, coloração da casca e da polpa, teor de açúcares e de ácidos, permanência dos frutos na planta, conservação após a colheita, transpiração das folhas, fertilidade do pólen, composição química das folhas, 
capacidade de absorção, síntese e utilização de nutrientes, tolerância à salinidade, resistência à seca e ao frio, resistência e tolerância a doenças e pragas.

O cultivo de mudas cítricas em ambiente protegido favorece a produção de plantas de elevada condição genética e sanitária. Esse cultivo necessita ser feito em recipientes, onde as mudas produzidas alteram seu desenvolvimento em função do meio de cultivo, quando comparado com o processo a campo, com a limitação de espaço para crescimento das raízes. Deste modo, o substrato deve possibilitar o perfeito desenvolvimento das raízes. Para isso, é necessário conhecer a qualidade do mesmo, através de suas características químicas, onde as mais importantes são o valor do $\mathrm{pH}$, os valores de macro e micro nutrientes disponíveis e a capacidade de trocas de cátions (FERMINO, 1996).

A utilização de substratos mais específicos para cada cultura proporciona melhor desenvolvimento da muda em menor intervalo de tempo, entretanto a melhor combinação de substratos tem que levar em conta a sustentabilidade, preferencialmente utilizando recursos disponíveis nas próprias propriedades rurais como: terriço, esterco bovino, serragem, casca de madeira e composto orgânico. O tipo de substrato é o primeiro aspecto que deve ser pesquisado para se garantir a produção de mudas de boa qualidade. O substrato exerce uma influência marcante na arquitetura do sistema radicular e no estado nutricional das plantas, afetando profundamente a qualidade das mudas (CARNEIRO, 1983).

Diante do exposto e da carência de projetos de pesquisa sobre porta-enxertos cítrico, direcionados para a realidade do Estado do Amazonas, o presente trabalho te- ve o objetivo de avaliar o comportamento inicial de seis porta-enxertos cítricos submetidos a cinco composições de substrato, em ambiente protegido.

\section{MATERIAL E MÉTODO}

O trabalho em questão foi desenvolvido em viveiro de mudas na área experimental da Coordenação de Pesquisas em Ciências Agronômicas (CPCA), do Instituto Nacional de Pesquisas da Amazônia (INPA), Manaus, Amazonas. Segundo Köppen apud Noronha (1996), o clima da área é do tipo equatorial quente e úmido "Afi". A casa de vegetação possui cobertura de filme plástico transparente com $150 \mu \mathrm{m}$ de espessura anti-UV e fechamento lateral com tela sombrite, com abertura de 0,87 $\mathrm{mm} \times 0,30 \mathrm{~mm}$. As bancadas de estrados de plásticos para produção de mudas foram instaladas a 0,4 $\mathrm{m}$ do piso para facilitar o manejo e aumentar a proteção contra contaminações por gomose de Phytophthora e nematoides.

Os porta-enxertos selecionados foram: o limoeiro Cravo "Santa Cruz" (Citrus limonia, L. Osbeck), as tangerineiras "Sunki comum" e "Sunki Tropical" (Citrus reticulata, Blanco), os híbridos de tangerinas Sunki x Trifoliata "Swingle 314", "English 264" e "English 256".

As sementes para a obtenção dos portaenxertos foram obtidas do Banco de Germoplasma da Embrapa Mandioca e Fruticultura, em Cruz das Almas, BA. Realizou-se a semeadura em bandejas de isopor furado com 72 células, utilizando como substrato a vermiculita expandida, por ser um material inerte, colocando três sementes por célula, em casa de vegetação da Coordenação de Pesquisa em Ciências Agronômicas - CPCA.

As plântulas dos seis porta-enxertos, 
após seleção e com aproximadamente altura de $10 \mathrm{~cm}$, foram transplantadas para os recipientes definitivos, sacolas plásticas de polietileno pretas, com espessura $200 \mu \mathrm{m}$, diâmetro de $8 \mathrm{~cm}$ e altura de $22 \mathrm{~cm}$, com capacidade para $2,5 \mathrm{dm}^{3}$, preenchidas com as diferentes composições de substratos.

Foram utilizadas cinco diferentes fontes de misturas para servirem de substrato para a formação das mudas, conforme Tabela 1; o solo utilizado como substrato no experimento foi a Terra Preta de Índio (TPI) classificada como Latossolo Amarelo com A antrópico de acordo com o Sistema Brasileiro de Classificação de Solos (EMBRAPA, 1999), ou ainda, solos antropogênicos, extraído da comunidade Costa do Laranjal, Iranduba $\mathrm{AM}$, coletado à profundidade de $0-30 \mathrm{~cm}$; já as fontes de matéria orgânica foram: o esterco bovino curtido (EBC) adquirido no IFAM - Campus Manaus Zona Leste, onde o mesmo já se encontrava em curtimento há mais de 10 meses; a serragem (S) oriunda de resto de madeira ainda não decomposta; tanto a casca de pinnus (CP) quanto a fibra de coco (FC) foram adquiridas em casas comerciais agrícolas da cidade. As diferentes composições de substratos foram esterilizadas em autoclave a $105^{\circ} \mathrm{C}$ por dois dias, sendo que, a cada dia ficou por 12 horas. Após 24 horas da esterilização, procedeu-se à mistura e o enchimento dos recipientes com as diferentes composições de substrato, conforme Tabela 1 . Foram retirados aproximadamente $300 \mathrm{~g}$ de cada composição de substratos para realizar a análise química, que apresentaram os resultados descritos na Tabela 2 .
Tabela 1. Fontes utilizadas para preparar cinco composições de substratos, com suas respectivas siglas, preparados no início do experimento de avaliação de comportamento de seis portaenxertos cítricos, em casa de vegetação. CPCA/INPA, Manaus.

Table 1. Sources used to prepare five compositions of substrates, with their respective acronyms, prepared at the beginning of the behavior evaluation experiment of six citrus rootstocks, under greenhouse conditions. CPCA / INPA, Manaus.

\begin{tabular}{|c|c|c|}
\hline FONTES DE SUBSTRATO & SIGLA & $\begin{array}{l}\text { COMPOSIÇÃO DE } \\
\text { SUBSTRATO (v/v) }\end{array}$ \\
\hline 1. Terra Preta de Índio (TPI) & TPI & TPI (100\%) \\
\hline $\begin{array}{l}\text { 2. TPI + Esterco de Boi } \\
\text { Curtido (EBC) }\end{array}$ & $\mathrm{TPI}+\mathrm{EBC}$ & TPI $(50 \%)+E B C(50 \%)$ \\
\hline 3. $\mathrm{TPI}+\mathrm{EBC}+$ Serragem (S) & TPI+EBC+S & $\begin{array}{l}\text { TPI (33\%) + EBC (33\%)+ } \\
\text { S (33\%) }\end{array}$ \\
\hline $\begin{array}{l}\text { 4. TPI + EBC + Casca de Pinus } \\
\text { (CP) }\end{array}$ & $\mathrm{TPI}+\mathrm{EBC}+\mathrm{CP}$ & $\begin{array}{l}\text { TPI (33\%) + EBC (33\%) + } \\
\text { CP (33\%) }\end{array}$ \\
\hline $\begin{array}{l}\text { 5. TPI + EBC + Fibra de Coco } \\
\text { (FC) }\end{array}$ & $\mathrm{TPI}+\mathrm{EBC}+\mathrm{FC}$ & $\begin{array}{l}\text { TPI (33\%) + EBC (33\%) + } \\
\text { FC (33\%) }\end{array}$ \\
\hline
\end{tabular}

Tabela 2 - Valores de pH e macronutrientes presentes nos substratos, coletados no início do experimento de avaliação de comportamento de seis porta-enxertos cítricos, em casa de vegetação. CPCA/INPA, Manaus.

Table 2 - $\mathrm{pH}$ values and macronutrients present in the substrates, collected at the beginning of the experiment to evaluate the behavior of six citrus rootstocks, under greenhouse conditions. CPCA / INPA, Manaus.

\begin{tabular}{|c|c|c|c|c|c|c|c|}
\hline TIPO DE & $\mathrm{P}$ & $\mathrm{Al}^{3+}$ & K & $\mathrm{Ca}$ & $\mathrm{Mg}$ & CTC & $\mathrm{C} / \mathrm{N}$ \\
\hline \multicolumn{3}{|c|}{ SUBSTRATO $\mathrm{mg} \cdot \mathrm{kg}^{-1}$} & \multicolumn{3}{|c|}{$\mathrm{cmol} \mathrm{kg}^{-1}$} & & \\
\hline TPI & 638,95 & 0,04 & 0,12 & 18,40 & 1,55 & 20,10 & 14,73 \\
\hline$T P I+E B$ & 583,55 & 0,12 & 8,15 & 20,53 & 6,06 & 34,86 & 11,73 \\
\hline$T P I+E B+S$ & 474,19 & 0,22 & 7,09 & 20,43 & 5,55 & 33,29 & 27,73 \\
\hline $\mathrm{TPI}+\mathrm{EB}+\mathrm{CP}$ & 504,67 & 0,2 & 9,58 & 24,50 & 8,16 & 42,44 & 17,49 \\
\hline$T P I+E B+F C$ & 554,86 & 0,32 & 13,28 & 19,99 & 5,53 & 39,12 & 14,40 \\
\hline
\end{tabular}

Os porta-enxertos foram conduzidos até alcançarem o diâmetro mínimo de $6 \mathrm{~mm}$ a $10 \mathrm{~cm}$ de altura, a partir do colo da planta, padrão citado por Carvalho (2003), o que levou em torno de 240 dias para que a maioria dos porta-enxertos alcançassem o mínimo exigido.

A irrigação foi realizada através de mangueira manual, medindo $10 \mathrm{~m}$, com bico tipo chuveiro, deixando 20 segundo em cada tratamento, tentando assim, manter a uniformidade de hidratação; sendo duas vezes ao dia, manhã e tarde, nos dias quentes, e apenas uma vez, nos dias chuvosos. A partir do terceiro mês, os porta-enxertos, principalmente os produzidos no substrato 
$\mathrm{TPI}+\mathrm{EBC}+\mathrm{S}$ apresentaram sintomas de deficiência de nitrogênio, procedendo então à aplicação de adubação foliar, com ureia na proporção de 5,0 $\mathrm{g} \mathrm{L}^{-1}$, quinzenalmente, conforme Boaretto et al., (1999). Também ocorreu ataque de pragas: minador (Phyllocnistis citrella Stainton), ácaro da gema (Aceria sheldoni Ewing) e moscanegra (Aleurocanthus woglumi Ashby), onde se aplicou os produtos, a cada 15 dias, Vertemec 18 CE e Provado200 SC, sendo que os dois tiveram as mesmas dosagens de aplicação $2 \mathrm{ml} / 6 \mathrm{~L}$; as pragas não chegaram a prejudicar o crescimento das mudas.

Avaliou-se a biometria tomando as seguintes medidas: a) altura das plantas utilizando fita métrica; b) diâmetro de caule dos porta-enxertos ao nível do substrato, com o auxílio de um paquímetro digital com precisão para $0,01 \mathrm{~mm}$; c) massa seca das raízes e parte aérea, após secagem do material vegetal em estufa de circulação forçada de ar a $60^{\circ} \mathrm{C}$, por $48 \mathrm{~h}$, e pesagem em balança eletrônica com precisão de 0,01 g; d) Número relativo de porta-enxertos aptos à enxertia, quando apresentavam um diâmetro superior a 7,00 $\mathrm{mm}$ ao nível do colo; significando que acima de $10 \mathrm{~cm}$ do colo possuíam diâmetro, em torno, de $6 \mathrm{~mm}$ (diâmetro mínimo para enxertia).

Os experimentos foram montados em delineamentos inteiramente casualizado em esquema fatorial $6 \times 5$. As médias obtidas foram comparadas pelo teste Anova ao nível de $5 \%$ de significância e quando apresentaram diferenças foram submetidas ao Teste Tukey ao nível de 5\% de significância. A variável percentagem de enxertia foi transformada com a seguinte fórmula $\mathrm{V} x$ conforme metodologia descrita por Ferreira (1991). Todos os dados foram analisados estatisticamente através do programa com- putacional Assistat, versão 7.2 (SILVA; AZEVEDO, 2002).

\section{RESULTADOS E DISCUSSÕES}

$\mathrm{Na}$ Tabela 3, nota-se diferença significativa somente para os efeitos simples dos substratos e dos porta-enxertos, para as variáveis altura e diâmetro; sendo estes os parâmetros mais importantes na citricultura, já que determinam o momento ideal para realização da enxertia, que quando mais cedo é realizada, mais rápida é a produção da muda, além disso, quanto maior é o diâmetro, maior serão as substâncias de reserva no caule (SALISBURY; ROSS, 1991). Os porta-enxertos "Santa Cruz", "English 264", "English 256" e "Swingle 314" apresentaram os maiores resultados de crescimento vegetativo para estas variáveis, não diferindo estatisticamente entre si, com exceção do "Swingle 314", para diâmetro, que diferiu estatisticamente destes. Durante os 240 dias de acompanhamento os porta-enxertos "Santa Cruz" e "English 264" tiveram uma taxa de crescimento em altura de $0,46 \mathrm{~cm} \cdot \mathrm{dia}^{-1}$, já os híbridos "English 256 " e "Swingle 314" de 0,42 cm.dia" ${ }^{-1}$; enquanto para diâmetro, o "Santa Cruz" obteve crescimento de 0,028 mm.dia-1, "English 264", "English 256" de 0,026 mm.dia ${ }^{-1}$ e "Swingle 314" de 0,024 mm.dia ${ }^{-1}$. Isso se explica por apresentarem maior vigor de crescimento, porque, o "Santa Cruz" é resultante de uma mutação natural de gema selecionada pela Embrapa Mandioca e Fruticultura, trazendo consigo alta carga genética do Limoeiro Cravo. Resultados semeIhantes foram encontrados por Mourão FiIho et al. (1998) avaliando os porta-enxertos limoeiro 'Cravo', Tangerina 'Cleópatra' e Citrumelo Swingle em cinco diferentes 
composições de substratos, constatou que o limoeiro 'Cravo' apresenta maior vigor para os parâmetros altura e diâmetro final avaliados. Ratificado por Moreira et al. (2000), avaliando o vigor de porta-enxertos para a produção de mudas de citros nas condições de Lavras, Minas Gerais, pode-se avaliar que o porta-enxerto limoeiro 'Cravo' produzido em fase de viveiro em citropotes, é mais precoce que os demais portaenxertos avaliados para as mesmas variáveis. Já os híbridos "English 264", "English 256" e "Swingle 314" por serem resultados de cruzamento genético entre tangerineira Sunki e trifoliata, que segundo Prudente e Silva (2006), através de suas pesquisas desenvolvidas constataram que esses híbridos apresentam comportamento vegetativo comparável ao limoeiro Cravo; e ratificado por Passos et al. (2006) caracterizando híbridos de trifoliata e outros porta-enxertos no Estado da Bahia também obtiveram valores semelhantes para os parâmetros avaliados. As tangerinas "Sunki comum" e "Tropical" apresentaram os piores resultados, diferindo estatisticamente para os "Santa Cruz", "English 264" em altura e para os "Santa Cruz", "English 264", "English 256" em diâmetro. Durante o período avaliado as "Sunki comum" e "Tropical" tiveram crescimento em altura de 0,34 e 0,38 $\mathrm{cm} \mathrm{dia}^{-1}$ e crescimento em diâmetro de 0,022 e 0,023 mm.dia-1, respectivamente, isso ocorreu, principalmente por apresentarem menor vigor em relação aos demais porta-enxertos. Silva, Souza e Sobrinho (2002), avaliando o comportamento inicial de dez porta-enxerto em viveiro nas regiões próximas a Manaus, obtiveram resultado semelhante, onde a tangerina Sunki comum apresentou os piores resultados para esses parâmetros.
Tabela 3 - Altura e diâmetro final dos porta-enxertos de citros produzidos em diferentes composições de substratos em sacos de polietileno, sob casa de vegetação. CPCA/INPA, Manaus, Am.

Table 3 - Height and final diameter of citrus rootstocks produced in different compositions of substrates in polyethylene bags, under greenhouse conditions. CPCA / INPA, Manaus, Am.

\begin{tabular}{|c|c|c|c|}
\hline \multicolumn{2}{|c|}{ TRATAMENTOS } & \multirow{2}{*}{$\begin{array}{c}\begin{array}{c}\text { ALTURA FINAL } \\
\text { (cm.planta-1) }\end{array} \\
120,19 a\end{array}$} & \multirow{2}{*}{$\begin{array}{c}\begin{array}{c}\text { DIÂMETRO } \\
\left(\mathrm{mm} \cdot \text { planta }^{-1}\right)\end{array} \\
8,35 \mathrm{a}\end{array}$} \\
\hline \multirow{6}{*}{ PORTA -ENXERTO } & Limoeiro cravo & & \\
\hline & English 264 & $116,92 \mathrm{a}$ & $7,77 \mathrm{ab}$ \\
\hline & English 256 & $108,36 a b$ & $7,88 \mathrm{ab}$ \\
\hline & Swingle 314 & $107,49 a b$ & $7,22 \mathrm{bc}$ \\
\hline & Sunki tropical & $96,49 \mathrm{bc}$ & $6,69 \mathrm{~cd}$ \\
\hline & Sunki comum & $85,21 \mathrm{c}$ & $6,45 d$ \\
\hline \multirow{5}{*}{ SUBSTRATOS } & TPI & $95,33 \mathrm{~b}$ & $7,15 \mathrm{bc}$ \\
\hline & $\mathrm{TPI}+\mathrm{EBC}$ & 116,78 a & $7,76 \mathrm{a}$ \\
\hline & $T P I+E B C+S$ & $93,17 \mathrm{~b}$ & $6,78 c$ \\
\hline & $T P I+E B C+C P$ & $109,43 a$ & $7,42 \mathrm{ab}$ \\
\hline & $T P I+E B C+F C$ & $114,18 \mathrm{a}$ & $7,86 \mathrm{a}$ \\
\hline \multicolumn{2}{|c|}{$\mathrm{CV}(\%)$} & 19,54 & 14,61 \\
\hline
\end{tabular}

${ }^{1}$ Médias seguidas por mesmas letras na coluna não diferem entres si pelo teste Tukey a $5 \%$ de probabilidade.

TPI: Terra Preta Antropogênica; EBC: Esterco bovino Curtido; S: Serragem; CP; Casca de pinus; FC: Fibra de Coco.

Os substratos $\mathrm{TPI}+\mathrm{EBC}, \mathrm{TPI}+\mathrm{EBC}+\mathrm{FC}$ e $\mathrm{TPI}+\mathrm{EBC}+\mathrm{CP}$ promoveram maior crescimento em altura e em diâmetro final aos portaenxertos, quando comparados aos substratos TPI e $\mathrm{TPI}+\mathrm{EBC}+\mathrm{S}$, diferindo estatisticamente para estes; isso se explica por dois fatores; o primeiro foi em relação à adição de matéria orgânica ao substrato que fez com que melhorasse as características físicas do solo favorecendo o crescimento das raízes e da planta, isso se comprova através da Tabela 2, que se observa CTC com valores de 34,86, 39,19 e 42,44 cmol. $\mathrm{kg}^{-1}$ para os substratos $\mathrm{TPI}+\mathrm{EBC}$, $\mathrm{TPI}+\mathrm{EBC}+\mathrm{FC}$ e $\mathrm{TPI}+\mathrm{EBC}+\mathrm{CP}$ sendo superiores aos demais, principalmente para o substrato TPI que não recebeu adição de fonte orgânica; o segundo foi a relação $\mathrm{C} / \mathrm{N}$ dos substratos, segundo Ballester-Olmos (1992) a relação $\mathrm{C} / \mathrm{N}$ acima de 30 faz com que o $\mathrm{N}$ fique imibilizado pelos microorganismos, causando deficiência desse nutrientes no substrato; este Ballester-Olmos (1992), recomenda que relação $\mathrm{C} / \mathrm{N}$ ideal é abaixo de 20 , sendo 
assim esse fator foi determinante para que o substrato $\mathrm{TPI}+\mathrm{EBC}+\mathrm{S}$, com uma relação $\mathrm{C} / \mathrm{N}$ de 27,73 Tabela 2, valor bem superior aos demais substratos, não expressasse todo seu potencial, não diferindo artisticamente para o substrato TPI.

A massa seca da parte aérea e radicular somente apresentou diferença significativa para os fatores substratos e porta-enxertos isoladamente Tabela 4, o porta-enxerto limoeiro cravo apresentou maior acúmulo de matéria seca tanto na parte aérea quanto na parte radicular, diferindo, estatisticamente, dos demais porta-enxertos, que apresentaram resultados semelhantes; tal resultado se explica, devido o porta-enxerto "Santa Cruz" apresentar maior vigor e precocidade, consequentemente, teve maior crescimento e, portanto, maior acúmulo de matéria seca. Fochesato et al., (2005) trabalhando com três porta-enxertos e três substratos na produção de mudas cítricas para o Rio Grande, do Sul obteve resultados diferentes, pois o limoeiro cravo somente apresentou resultados intermediários para essa variável, provavelmente, por ser uma variedade não tolerante a temperaturas amenas. As tangerineiras "Sunki comum" e "Sunki Tropical", por apresentarem menor vigor e precocidade expressaram menor acúmulo de matéria seca em relação ao limoeiro Cravo Santa Cruz, mas não diferiu estatisticamente para os híbridos "English 264", "English 256" e "Swingle 314"; essas por sua vez, ao contrário dos parâmetros analisados na Tabela 3, apresentaram resultados inferiores ao "Santa Cruz", isso se deve por possuir menor área foliar do que os demais porta-enxerto, que é uma característica intrínseca desta espécie, por serem híbridos de trifoliata tem folhas compostas. Segundo Marengo (2009) são características marcantes desta espécie possuir limbo foliar dividido em três folíolos e caducifólias. Fochesato et al., (2007), avaliando o crescimento de porta-enxertos de citros produzidos em substratos comerciais, obtiveram resultados semelhantes para a espécie trifoliata.

Já os substratos TPI+EBC, TPI+EBC+CP e $\mathrm{TPI}+\mathrm{EBC}+\mathrm{FC}$, mantiveram as mesmas análises da Tabela 3 e proporcionaram às plantas maiores acúmulos de matéria seca, tanto na parte aérea quanto na parte radicular, principalmente pela adição de matéria orgânica aos substratos; já os substratos TPI e $\mathrm{TPI}+\mathrm{EBC}+\mathrm{S}$ proporcionaram os piores resultados para estes parâmetros, o primeiro pela não adição de matéria orgânica e o segundo pela alta relação $\mathrm{C} / \mathrm{N}$.

Tabela 4 - Massa seca da parte aérea e radicular dos portaenxertos de citros produzidos em diferentes composições de substratos em sacos de polietileno, sob casa de vegetação. CPCA/INPA, Manaus, Am.

Table 4 - Dry mass of shoot and root of citrus rootstocks produced in different compositions of substrates in polyethylene bags, under greenhouse conditions. CPCA / INPA, Manaus, Am.

\begin{tabular}{|c|c|c|c|}
\hline \multirow{2}{*}{\multicolumn{2}{|c|}{ TRATAMENTOS }} & \multicolumn{2}{|c|}{ MASSA SECA (g. planta) } \\
\hline & & Parte Aérea & Raiz \\
\hline \multirow{6}{*}{ PORTA -ENXERTO } & Limoeiro cravo & 31,69 a & 18,15 a \\
\hline & Sunki tropical & $20,30 \mathrm{~b}$ & $8,27 \mathrm{~b}$ \\
\hline & English 256 & $19,95 \mathrm{~b}$ & $8,50 \mathrm{~b}$ \\
\hline & English 264 & $20,59 \mathrm{~b}$ & $8,84 \mathrm{~b}$ \\
\hline & Swingle 314 & $18,82 \mathrm{~b}$ & $6,12 b$ \\
\hline & Sunki comum & $18,42 \mathrm{~b}$ & $7,61 \mathrm{~b}$ \\
\hline \multirow{5}{*}{ SUBSTRATOS } & TPI & $17,55 \mathrm{~b}$ & $8,10 \mathrm{bc}$ \\
\hline & $T P I+E B C$ & 24,51 a & $10,80 \mathrm{ab}$ \\
\hline & $T P I+E B C+S$ & $17,52 \mathrm{~b}$ & $7,49 \mathrm{c}$ \\
\hline & $\mathrm{TPI}+\mathrm{EBC}+\mathrm{CP}$ & $22,36 a b$ & $9,29 a b c$ \\
\hline & $T P I+E B C+F C$ & $26,22 \mathrm{a}$ & $12,23 \mathrm{a}$ \\
\hline \multicolumn{2}{|c|}{$\mathrm{CV}(\%)$} & 15,17 & 23,04 \\
\hline
\end{tabular}

1 Médias seguidas por mesmas letra na coluna não diferem entres si pelo teste Tukey a $5 \%$ de probabilidade.

TPI: Terra Preta Antropogênica; EBC: Esterco bovino Curtido; S: Serragem; CP; Casca de pinus; FC: Fibra de Coco.

O número de porta-enxertos aptos à enxertia apresentado na Tabela 5, sofreram interação entre os fatores porta-enxerto e substratos, apesar dos valores absolutos, em alguns casos, serem diferentes, o teste 
de média, na maioria das vezes não indica diferença. O porta-enxerto, "Sunki comum", quando submetido ao substrato $\mathrm{TPI}+\mathrm{EBC}+\mathrm{S}$ foi a única combinação que apresentou o pior resultado, diferindo estatisticamente para os demais, isso se explica devido à alta relação $\mathrm{C} / \mathrm{N}$ presente neste substrato Tabela 2, combinado com suas características genotípicas, o que resultou num menor crescimento. O porta-enxerto "Sunki tropical", apesar de ter apresentado resultados inferiores para as variáveis analisadas anteriormente, conseguiu atingir o diâmetro mínimo para enxertia após 240 dias depois da repicagem, que é de $6 \mathrm{~mm}$ conforme citação de Carvalho (2003), pelo menos 75\% estavam aptas a enxertar nos substratos TPI e TPI +EBC. O substrato TPI +EBC+S, apesar de ter sido inferior aos demais substratos, é promissor, pois é um ingrediente de fácil acesso pelo pequeno agricultor, o que necessita é ter um manejo diferenciado dos demais, ou seja, uma prévia decomposição deste antes de ser adicionado no substrato, diminuído assim, sua relação $\mathrm{C} / \mathrm{N}$.

Tabela 5 - porcentagem de porta-enxertos aptos à enxertia, produzidos em diferentes composições de substratos em sacos de polietileno, sob casa de vegetação. CPCA/INPA, Manaus, Am.

Table 5 - Percentage of rootstocks suitable for grafting, produced in different compositions of substrates in polyethylene bags, under greenhouse. CPCA / INPA, Manaus, Am.

\begin{tabular}{|c|c|c|c|c|c|}
\hline \multirow{3}{*}{$\begin{array}{l}\text { PORTA- } \\
\text { ENXERTOS }\end{array}$} & \multicolumn{5}{|c|}{ PLANTAS APTAS À ENXERTIA (\%) } \\
\hline & \multicolumn{5}{|c|}{ SUBSTRATOS } \\
\hline & TPI & $\mathrm{TPI}+\mathrm{EBC}$ & $\begin{array}{c}\mathrm{TPI}+\mathrm{EBC}+ \\
\mathrm{S}\end{array}$ & $\begin{array}{c}\mathrm{TPI}+\mathrm{EBC}+ \\
\mathrm{CP}\end{array}$ & $\begin{array}{c}\text { TPI + } \\
\mathrm{EBC}+\mathrm{FC}\end{array}$ \\
\hline Limoeiro cravo & $100,00 \mathrm{aA}$ & $100,00 \mathrm{aA}$ & 87,50 aA & $100,00 \mathrm{aA}$ & 100,00 aA \\
\hline Sunki tropical & $75,00 \mathrm{aA}$ & $75,00 \mathrm{aA}$ & $100,00 \mathrm{aA}$ & $87,50 \mathrm{aA}$ & $100,00 \mathrm{aA}$ \\
\hline English 256 & $100,00 \mathrm{aA}$ & $100,00 \mathrm{aA}$ & $75,00 \mathrm{abA}$ & $100,00 \mathrm{aA}$ & 100,00 aA \\
\hline English 264 & $100,00 \mathrm{aA}$ & $100,00 \mathrm{aA}$ & $100,00 \mathrm{aA}$ & $87,50 \mathrm{aA}$ & 100,00 aA \\
\hline Swingle 314 & $100,00 \mathrm{aA}$ & $100,00 \mathrm{aA}$ & $100,00 \mathrm{aA}$ & $100,00 \mathrm{aA}$ & $100,00 \mathrm{aA}$ \\
\hline Sunki comum & $87,50 \mathrm{aA}$ & $100,00 \mathrm{aA}$ & $50,00 \mathrm{bB}$ & $87,50 \mathrm{aA}$ & $100,00 \mathrm{aA}$ \\
\hline$\overline{C V(\%)}$ & & & 8,33 & & \\
\hline
\end{tabular}

${ }^{1}$ Médias seguidas por mesmas letras, maiúscula na linha e minúscula na coluna, não diferem entres si pelo teste Tukey a $5 \%$ de probabilidade. TPI: Terra Preta Antropogênica; EBC: Esterco bovino Curtido; S: Serragem; CP; Casca de pinus; FC: Fibra de Coco.

\section{CONCLUSÃO}

Os porta-enxertos limoeiro cravo "Santa Cruz", e os híbridos "English 264", "English 256" e "Swingle 314" são promissores para a citricultura Amazonense.

Os substratos $\mathrm{TPI}+\mathrm{EBC}, \mathrm{TPI}+\mathrm{EBC}+\mathrm{CP}$ e $\mathrm{TPI}+\mathrm{EBC}+\mathrm{FC}$ são os mais recomendados para os porta-enxertos acima, nas condições analisadas.

No substrato $\mathrm{TPI}+\mathrm{EBC}+\mathrm{S}$, a serragem necessita ser decomposta antes de ser adicionada na composição do substrato.

Os porta-enxertos promissores necessitam ser avaliados em campo, visando ratificar a transmissão aos enxertos do vigor e precocidade, além de outras características desejáveis.

\section{REFERÊNCIAS}

ALMUDI, T.; PINHEIRO, J. O. C. Dados Estatísticos da Produção Agropecuária e Florestal do Estado do Amazonas. EMBRAPA, Brasília, 2013. Disponível em: <https://www.bd pa.cnptia.embrapa.br/consulta/busca?b=pc \&biblioteca=vazio\&busca=autoria:\%22ALM UDI,\%20T.\%22>. Acesso em: 11 jul. 2017. ANDRADE, R. A.; MARTINS, A. B. G. Propagação vegetativa de porta-enxertos para citros. Revista Brasileira de Fruticultura, Jaboticabal, São Paulo, v. 25, n. 1, p. 134136, 2003.

BOARETTO, A. E.; MURAOKA, T.; OLIVEIRA, M. W. Adubação foliar corretiva e preventiva em citros. Revista Laranja, Cordeirópolis, v. 20, n. 1, p. 233-250, 1999.

BALLESTER-OLMOS, J. F. Substratos para el cultivo de plantas ornamentales. Valencia: Instituto Valenciano de Investigaciones Agrárias, 1992. 44p. (Hojas Divulgadoras, 11). 
CARNEIRO, J. G. de A. Variações na metodologia de produção de mudas florestais afetam os parâmetros morfofisiológicos que indicam a sua qualidade. Curitiba: FUPEF, 1983. (Série Técnica, 12).

CARVALHO, S. A. Regulamentação Atual da Agência de Defesa Agropecuária para Produção, Estocagem, Comércio, Transporte e Plantio de Mudas Cítricas no Estado de São Paulo. Laranja, Cordeirópolis, v. 24, n. 1, p. 199-239, 2003.

EMPRESA BRASILEIRA DE PESQUISA AGROPECUÁRIA: CENTRO NACIONAL DE PESQUISA DE SOLO. Sistema Brasileiro de Classificação de Solos. Rio de Janeiro: EMBRAPA Solos, 1999.

FERREIRA, P. V. Estatística experimental aplicada à agronomia. Maceió: EDUFAL, 1991.

FERMINO, M. H. Aproveitamento de resíduos industriais e agrícolas como alternativas de substratos hortícolas. 1996. $90 \mathrm{f}$. Dissertação de Mestrado em Fitotecnia Universidade Federal do Rio Grande do Sul. Rio Grande do Sul. 1996.

FOCHESATO, M. L. Substratos e portaenxertos na produção de mudas cítricas em ambiente protegido. 2005. $91 \mathrm{f}$. Dissertação de Mestrado em Fitotecnia - Universidade Federal do Rio Grande do Sul, Rio Grande do Sul. 2005.

FOCHESATO, M. L. et al. Crescimento vegetativo de porta-enxertos de citros produzidos em substratos comerciais. Ciência Rural, v. 37, n. 4, p. 970-975, 2007. https://doi. org/10.1590/S0103-84782007000400008

GRAF, C. C. D. Vivecitrus e a produção de mudas certificadas. Laranja, v. 22, n. 2, p. 549-559, 2001.

INSTITUTO BRASILEIRO DE GEOGRAFIA DE ESTATÍSTICA - IBGE. Produção Agrícola Municipal: Culturas Temporárias e Permanen- tes. Pesq. agric. munic., Rio de Janeiro, v. 43, n. 1, p. 1-62. 2016.

KÖPPEN, W. Classificação climática. Apud NORONHA, M. C. O espaço geográfico do Amazonas. Concorde, Porto Alegre: RS, 1996. p. 34-42.

LEDO, A. DA S. et al. Porta-enxertos para laranjeiras-doces (Citrus sinensis (L.) Osb.). Pesq. agropec. bras., v. 34, n. 7, p. 12111216, 1999.

MARENGO, S. Mapeamento genético de tangerina Sunki e Poncirus trifoliata para resistência ao huanglongbing (greening) dos citros. Tese (Mestrado em Agricultura Tropical e Subtropical) - Piracicaba-SP, Escola Superior de Agricultura "Luiz de Queiroz"ESALQ, 129 f. 2009.

MOREIRA, A. et al. Avaliação de Diferentes Porta-enxertos de Citros Cultivados em Citropotes. Ciênc. Agrotec., v. 24, n. 2, p. 504508, 2000.

MOURÃO FILHO, F. A. A. et al. Efeito da Composição do Substrato na Formação de Mudas de Laranjeira 'Pêra'. Sci. Agric., v. 55, n. 1, 1998. https://doi.org/10.1590/S0103$\underline{90161998000100007}$

NEVES, M. F.; TROMBIN, V. G. Anuário da Citricultura. São Paulo, CITRUSBR, 2017. Disponível em: <http://www.citrusbr.com/ download/biblioteca/Apresentacao Marcos Fava evento valor.pdf $>$. Acesso em: 11 jul. 2017.

OLIVEIRA, R. P. et al. Características dos principais porta-enxertos recomendadas para citros no Rio Grande do Sul. Pelotas, RS. p.1-7. (Comunicado Técnico, 128), 2005. OLIVEIRA, T. K. Produção de Mudas de Citros. In: PEREIRA, J. E. S. Produção de Mudas de Espécies Agroflorestais: banana, açaí, abacaxi, citros, cupuaçu e pupunha. Embrapa Acre, Rio Branco, Acre. p. 23-28. 2003. (Documentos, 89). 
PASSOS, O. S. et al. Caracterização de híbridos de Poncirus Trifoliata e de outros portaenxertos de citros no Estado da Bahia. Revista Brasileira de Fruticultura, v. 28, n. 3, p. 410-413, 2006. https://doi.org/10.1590/ $\underline{\text { S0100-29452006000300016 }}$

POMPEU JR., J. Porta-enxertos. In: RODRIGUEZ, O. et al. Citricultura brasileira. Campinas, São Paulo, Fundação Cargill, Vol.1, 1991. p.265-280.

PRUDENTE, R. M.; SILVA, L. M. S. Portaenxertos cítricos. In: MELO, M. B.; SILVA, L. M. S. Aspectos técnicos dos citros em Sergipe. Aracaju, Sergipe, Embrapa Tabuleiros Costeiros, 2006. p. 41-49.

SALISBURY, F. B.; ROSS, C. W. Plant Physiology. 4 ed. California: Wadsworth publishing, 682p. 1991.

SCHÄFER, G. et al. Desenvolvimento vegetativo inicial de porta-enxertos cítricos cultivados em diferentes substratos. Ciência Rural, v. 36, n. 6, p. 1723-1729, 2006. https: //doi.org/10.1590/S0103-84782006000600009 SILVA, S. E. L. DA; GARCIA, T. B. A cultura da laranjeira no Amazonas. Embrapa Amazônia Ocidental, Manaus, Amazonas. 20p. (Documentos, 5). 1999.

SILVA, F. A. S.; AZEVEDO, C. A. V. Versão do programa computacional Assistat para o sistema operacional Windows. Revista Brasileira de Produtos Agroindustriais, v. 4, n. 1, p. 71-78, 2002. https://doi.org/10.15871/ 1517-8595/rbpa.v4n1p71-78

SILVA, E. L. S.; SOUZA, A. G. C.; SOBRINHO, A. P. C. Comportamento inicial de dez porta-enxertos para a lima ácida Tahiti nas regiões próximas a Manaus, Amazonas. Manaus, 2002. Disponível em: <https://ww w.embrapa.br/amazonia-ocidental/buscade-publicacoes/-/publicacao/671966>. Aces -so em: 27 jul. 2017.

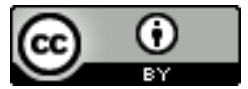

License information: This is an openaccess article distributed under the terms of the Creative Commons Attribution License, which permits unrestricted use, distribution, and reproduction in any medium, provided the original work is properly cited.

Artigo recebido em 06 de junho de 2018.

Avaliado em 29 de junho de 2018.

Aceito em 23 de julho de 2018.

Publicado em 27 de fevereiro de 2019.

\section{Como citar este artigo (ABNT):}

NASCIMENTO, Carlos Alberto Fonseca do; MARTEL, Jorge Hugo Iriarte; PLÁCIDO JúNIOR, Cristóvão Gomes. Comportamento de porta-enxertos cítricos submetidos em composições de diferentes substratos. Estação Científica (UNIFAP), Macapá, v. 8, n. 2, p. 47-56, maio/ago. 2018. 